\title{
Application of Background Information Database in Trend Change of Agricultural Land Area of Guangxi
}

\author{
Xin Yang ${ }^{1, *}$, Shiquan Zhong ${ }^{1,2}$, Yuhong $\mathrm{Li}^{1,2}$, \\ Weiping $\mathrm{Lu}^{1,2}$, and Chaohui $\mathrm{Wu}^{1,2}$ \\ ${ }^{1}$ Remote Sensing Application and Test Base of National Satellite Meteorology Centre, \\ Nanning, China, 530022 \\ ${ }^{2}$ GuangXi Institute of Meteorology, Nanning, 530022, P.R. China \\ Tel.:+86-771-5875207; Fax: +86-771-5865594 \\ yangxinzhuanyong@sina.com
}

\begin{abstract}
Guangxi Province is one of the regions more serious desertification. This paper using ENVI image processing system, according to remote sensing image interpretation target mark and image spectral characteristics, found remote sensing interpretation model of the background information of forest, shrub and grass, agricultural land, surface water, towns, roads from TM and ETM data from 1988 to 2008, using supervision, unsupervised, maximum classification of natural law to retrieve background information from simple to complex interpretation of each classification. Meanwhile, using human-computer interaction to refine the results. The output shp format data Vector file of disaggregated data edited in the GIS system, and get the background information on various types of remote sensing data each time. The result showed that agricultural land area showed a decreasing trend, but change is not very significant.
\end{abstract}

Keywords: background information, agricultural land area, trend change.

\section{Introduction}

China's natural resources, especially arable land resources is one of the major constraints facing severe shortage of long-term survival and development. The constant decrease of cultivated land resources arouses the extensive attentions of society at home and abroad. As the increasingly urgent problem of food security, urbanization and agricultural development and environmental pressure on the contradictions, land

\footnotetext{
* Corresponding author.
} 
resource protection to ensure national food security has become an important basic work. With the development of satellite remote sensing technology, remote sensing has become an important means of land access to information. Many studies on land use/cover changes had been carried out by researchers from all over the world since the first earth resource satellite was launched in 1970s in the United States. Land use/cover maps for the urban area of Boston were produced at level III of Anderson et al. (1972) scheme using large format camera shuttle photographs and national high altitude photographs. The accuracy of them was $65 \%$ and $70 \%$ respectively (Lo \& Noble, 1990). The potential of SPOT XS images were tested for automatically outlining agricultural near-urban interfaces for an area around Yogyakarta, Central Java, and satisfying results were gotten which were comparable to those obtained from visual interpretation of 1:100000 near-infrared aerial photographs (GastelluEtchegorry, 1990). Eight land covers were mapped at level of Anderson scheme on the urban fringe in England from Landsat MSS data (Curran \& Pedley, 1990). $10 \mathrm{~m}$ resolution of the SPOT panchromatic band was used by registering it with the multispectral ones to obtain a classification of eight land covers at the urban- rural fringe of Toronto, Canada with an accuracy of 78\% (Treitz et al., 1992). Five-category classification was obtained in the small urban area of Beaver Dam, Winsconsin (Harris \& Entura, 1995). Detailed land cover maps were produced at the urban-rural periphery in southern Auckland using Spot XS data (Gao \& Skillcorn, 1998). Using TM imagery residential areas were extracted with simple threshold of spectrum structure (Yang \& Zhou, 2000). From TM imagery using normalized difference built-up index, the urban land-use map of Wuxi city was achieved (Zha, 2003).

The present paper using ENVI image processing system, according to remote sensing image interpretation target mark and image spectral characteristics, found remote sensing interpretation model of the background information of forest, shrub and grass, agricultural land, surface water, towns, roads from TM and ETM data from 1988 to 2008 , using supervision, unsupervised, maximum classification of natural law, from simple to complex interpretation of each classification. Meanwhile, using humancomputer interaction to refine the results. The output shp format data Vector file of disaggregated data edited in the GIS system, and get the background information on various types of remote sensing data each time.

\section{Materials and Methods}

\subsection{Study Area}

Guangxi $\left(104^{\circ} 28^{\prime}-112^{\circ} 03^{\prime} \mathrm{E}, 20^{\circ} 54^{\prime}-26^{\circ} 23^{\prime} \mathrm{N}\right)$, a city in South China, has an area of about 236,700 km2 (Fig.1). It belongs to the Subtropical monsoon climate region, annual average temperate is $16.0^{\circ} \mathrm{C}-22.0^{\circ} \mathrm{C}$, and annual mean precipitation is $1200-1800 \mathrm{~mm}$. 


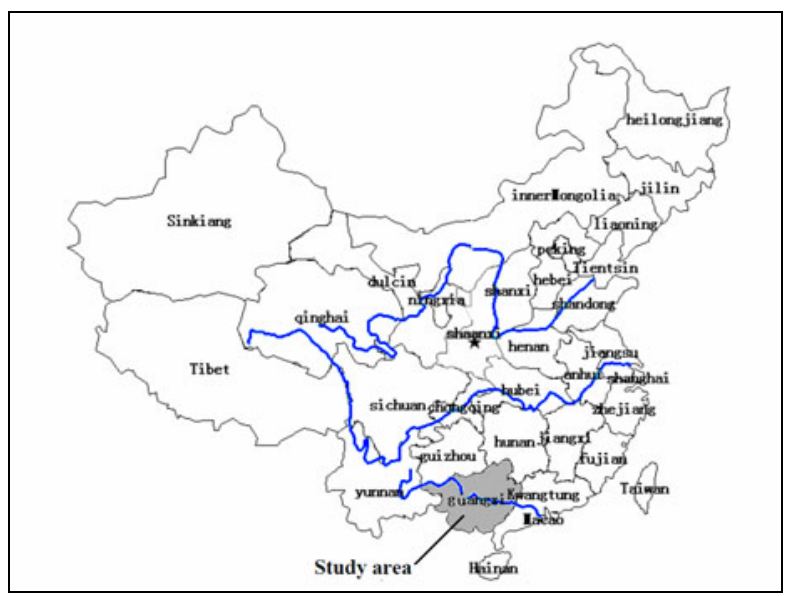

Fig. 1. Location of study area

\subsection{Data Acquisition}

In this study, Landsat ETM/TM images from 1986 to 2008 were required. List of the orbit data is in Table 1, and their spatial resolution is $30 \mathrm{~m}$.

Table 1. List of the orbit data

\begin{tabular}{lllll}
\hline Orbit data & $\begin{array}{l}\text { Image } \\
\text { Time(TM) }\end{array}$ & $\begin{array}{l}\text { Image } \\
\text { Time(TM) }\end{array}$ & $\begin{array}{l}\text { Image } \\
\text { Time(ETM) }\end{array}$ & $\begin{array}{l}\text { Image } \\
\text { Time(TM) }\end{array}$ \\
\hline $123 / 43$ & $1988-12-07$ & $1991-09-09$ & $2001-12-29$ & $2006-12-19$ \\
$123 / 44$ & $1988-12-17$ & $1994-05-08$ & $2001-12-29$ & $2006-12-19$ \\
$124 / 42$ & $1986-11-01$ & $1998-10-01$ & $2002-01-05$ & $2008-11-13$ \\
$124 / 43$ & $1986-11-01$ & $1998-10-01$ & $2002-01-05$ & $2008-11-13$ \\
$124 / 44$ & $1986-11-01$ & $1998-10-17$ & $2002-01-05$ & $2008-11-13$ \\
$124 / 45$ & $1986-11-01$ & $1998-10-17$ & $2001-11-18$ & $2008-11-13$ \\
$125 / 42$ & $1987-10-26$ & $1998-10-24$ & $2001-11-25$ & $2008-05-12$ \\
$125 / 43$ & $1987-10-26$ & $1998-10-24$ & $2002-10-11$ & $2008-05-12$ \\
$125 / 44$ & $1986-11-24$ & $1998-10-24$ & $2002-10-11$ & $2008-11-20$ \\
$125 / 45$ & $1988-11-29$ & $1998-10-24$ & $2002-10-11$ & $2008-11-20$ \\
$126 / 42$ & $1988-09-17$ & $1999-09-24$ & $2002-08-31$ & $2008-11-27$ \\
$126 / 43$ & $1988-10-19$ & $1998-10-15$ & $2002-08-31$ & $2008-11-11$ \\
$126 / 44$ & $1986-10-30$ & $1998-10-15$ & $2001-11-16$ & $2008-11-11$ \\
$126 / 45$ & $1988-03-07$ & $1998-10-15$ & $2001-09-29$ & $2008-11-11$ \\
$127 / 42$ & $1988-11-11$ & $1998-11-07$ & $2001-11-23$ & $2008-12-20$ \\
$127 / 43$ & $1988-11-11$ & $1998-11-07$ & $2001-11-23$ & $2008-03-23$ \\
$127 / 44$ & $1988-11-11$ & $1998-11-07$ & $2001-11-23$ & $2008-03-23$ \\
$128 / 43$ & $1987-03-21$ & $1997-11-27$ & $2002-04-07$ & $2006-04-10$ \\
\hline & & & &
\end{tabular}




\subsection{Data Processing}

The basic idea of this research was to retrieve forest, shrub and grass, agricultural land, surface water, towns, Rocky Desertification, roads of different image phases using Landsat ETM/TM data, and then to map the agricultural land , finally to analyse the trend of agricultural land change (Fig. 2).

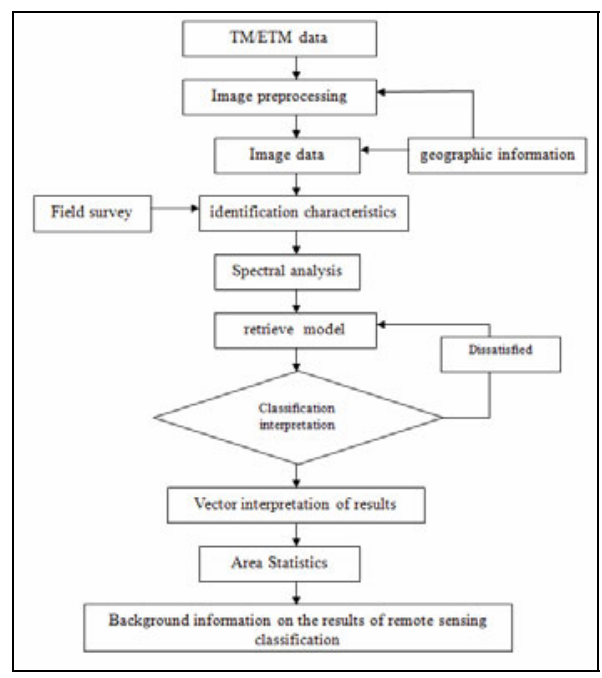

Fig. 2. The flow chart of background information of remote sensing classification

Detailed illustration of data processing was as follows:

- Imagery pre-processing

The pre-processing included atmospheric correction, geometric correction, and orthographic correction. The purpose of atmospheric correction was to obtain accurate reflective characteristics of ground surface, followed by geometric correction which ground control points were chosen referencing to a topographic map of 1:50,000. To efficiently reduce the topographic effect on solar radiation, DEM was employed to promote orthographic correction on remote sensing images.

- Retrieval of background information

In this research, supervision, unsupervised, maximum classification of natural law were used to retrieve background information.

- Mapping background information of Guangxi

Background information were mapped by using supervision, unsupervised, maximum classification of natural law. Then the change of agricultural land area from 1986 to 2008 can be acquired. 


\section{Retrieval of Background Information Classes}

From the spectrum feature of ground, band $4(0.76-0.90 \mu \mathrm{m})$ of TM/ETM+ is the near infrared waveband which reflects vegetation information. Thus this band is very sensitive to detect vegetation, while reflectance of barren and residential areas in this band is low. ETM/TM5 $(1.55-1.75 \mu \mathrm{m})$, the shortwave infrared waveband, can reflect the information of moisture content in different land use types. For example, in band5 the reflectance of forest and farmland with high moisture content is low, but for residential and barren areas that have low moisture content, the reflectance is high. Researches indicated that on Landsat TM/ETM+ images, except urban and barren areas, the digital numbers of other landscape in band 4 are lower than that of band 5 (Yang, 2000, Zha, 2003).Supervised classification is the most common method in obtaining land use/cover information. In this research, after data pre-processing, training samples were selected according to the band spectral curves of target objects(Fig.3).

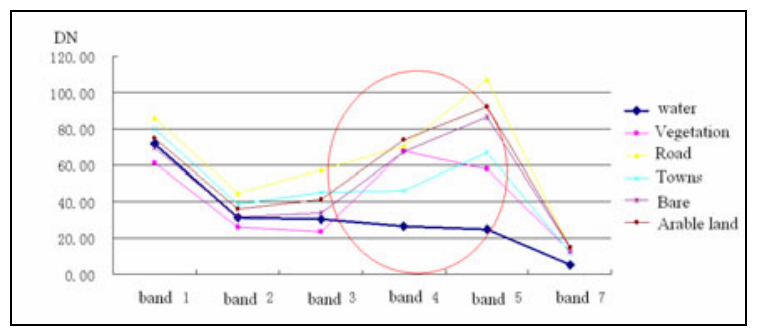

Fig. 3. Band spectral curves of target objects

Unlike conventional classification of land use/cover, in this paper, only six classifications of land cover were chosen, which were forest, shrub and grass, agricultural land, surface water, towns, roads . At the same time, we use human-computer interaction to refine the results. This could avoid the background information classes(Fig.4). Then maximum likelihood classification was used to map the agricultural land of Guangxi(Fig. 5).

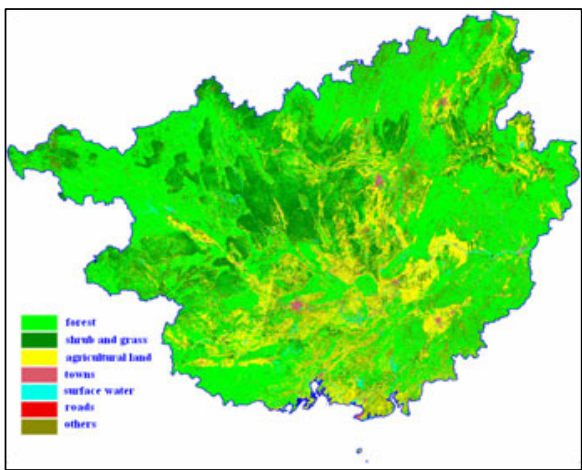

Fig. 4. Background information classes

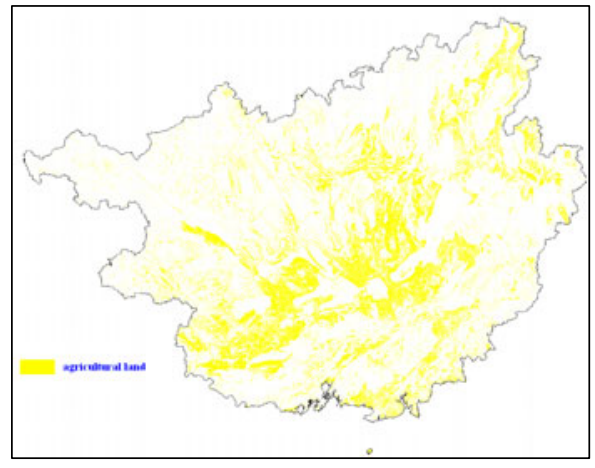

Fig. 5. Distribution of agricultural land 
It can be seen from the report provided by the software of ENVI, the overall accuracy of classification can be acquired (Table.2). Fig. 6 is the field survey itinerary.

Table 2. Accuracy analysis of classification results

\begin{tabular}{llll}
\hline Classes & Total survey & $\begin{array}{l}\text { Correctly } \\
\text { classified }\end{array}$ & $\begin{array}{l}\text { Accuracy } \\
(\%)\end{array}$ \\
\hline $\begin{array}{l}\text { forest } \\
\begin{array}{l}\text { Shrub and } \\
\text { grass }\end{array}\end{array}$ & 26 & 22 & 84.62 \\
$\begin{array}{l}\text { Agricultural } \\
\text { land }\end{array}$ & 42 & 94 & 88.68 \\
$\begin{array}{l}\text { Surface } \\
\text { water }\end{array}$ & 28 & 37 & 88.09 \\
towns & 50 & 26 & 92.86 \\
roads & 46 & 43 & 86.00 \\
\hline
\end{tabular}

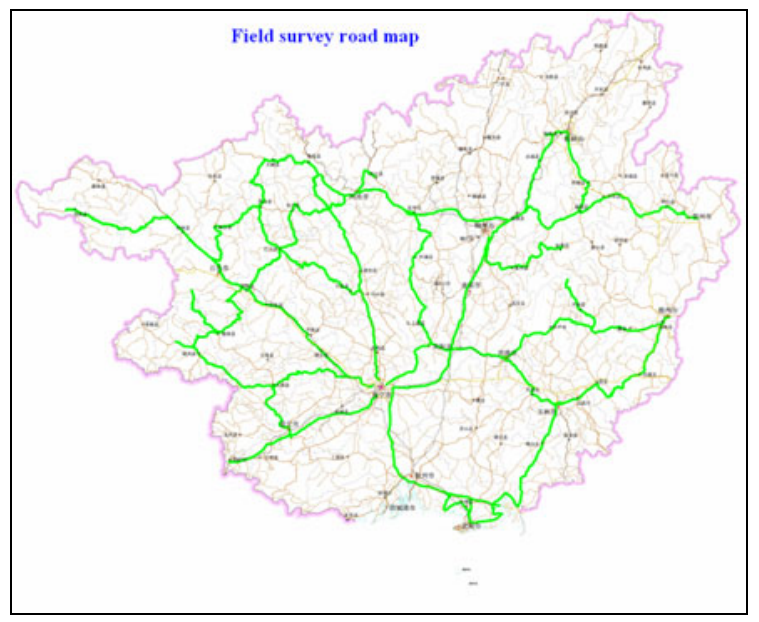

Fig. 6. Field survey itinerary

Fig.7 is the area of agricultural land of Guangxi from 1988 to 2008.

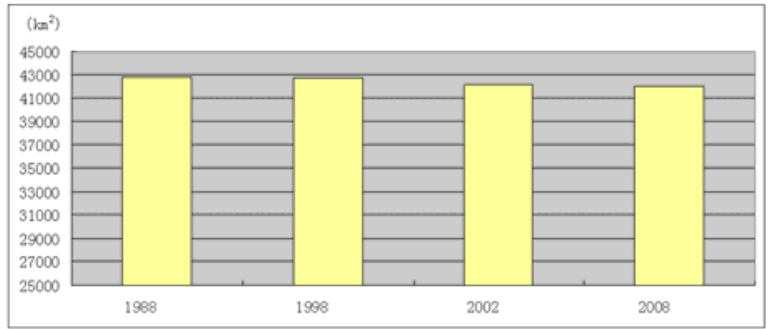

Fig. 7. Area of agricultural land 


\section{Discussion and Conclusion}

By analyzing the change of agricultural land area of Guangxi from 1986 and 2008 resulted from supervised classification, we can find that during the 20 years, agricultural land area has decrease $732.8 \mathrm{~km} 2$ from $42767.3 \mathrm{~km} 2$ to $42034.5 \mathrm{~km} 2$, showed a decreasing trend, but the change is not very significant. This change was driven by many factors. however human activity was the most important one. Rapid economic development and fast urbanization was the fundamental reasons. A lot of farmland were used to build large scale constructions of infrastructures.

\section{Acknowledgments}

This research was supported by Scientific Research and Technological Development projects of Guangxin Province (0816006-8) and National 11th Five-Year Plan major scientific and National Key Technologies R\&D Program (2008BAD08B01), Sincerely thanks are also due to Guangxi Climate center and National Satellite Meteorology Center for providing the data for this study.

\section{References}

1. Bruzzone, L.: Detection of changes in remotely-sense images by the selective use of multispectral information. Int. J. Remote Sensing 18, 3883-3888 (1997)

2. Curran, P.J., Pedley, M.I.: Airborne MSS for land cover classification II. Geocarto International 5, 15-26 (1990)

3. Charbonneau, L., Morin, D., Royer, A.: Analysis of different methods for monitoring the urbanization process. Geocarto International 8, 17-25 (1993)

4. Chen, X.J., Zhang, H.Y., Liu, S.H.: A study on the macro mechanism of the conversion of land use in the urban fringe of Beijing. Progress in Geography 22, 149-157 (2003) (Chinese)

5. Dai, C., Lei, L.: The Information Characteristics of Thematic Mapper Data and the Optimal Band Combination. Remote Sensing of environment 4, 282-292 (1989)

6. Gao, B.C.: NDVI-a normalized difference water index for remote sensing of vegetation liquid water from space. Remote Sensing of Environment 58, 257-266 (1996)

7. Gao, J., Skillcorn, D.: Capability of SPOT XS data in producing detailed land cover maps at the urban-rural periphery. International Journal of Remote Sensing 19, 2877-2891 (1998)

8. Gastellu-Etchegorry, J.P.: An assessment of SPOT XS and Landsat MSS data for digital classification of near-urban land cover. International Journal of Remote Sensing 11, 225235 (1990)

9. Harris, P.M., Ventura, S.J.: The integration of geographic data with remotely sensed imagery to improve classification in an urban area. Photogrammetric Engineering and Remote Sensing 61, 993-998 (1995)

10. Lo, C.P., Noble Jr., E.: Detailed urban land-use and land-cover mapping using large format camera photographs: an evaluation. Photogrammetric Engineering and Remote Sensing 56, 197-206 (1990) 
11. Mcffters, S.K.: The use of the Normalized Difference Water Index (NDVI) in the delineation of open water features. International Journal of Remote Sensing 17, 1425-1432 (1996)

12. Sidjak, R.W., Wheate, R.D.: Glacier mapping of the Illecillewaet icefield, British Columbia, Canada, using Landsat TM and digital elevation data. International Journal of Remote Sensing 20, 273-284 (1999)

13. Treitz, P.M., Howarth, P.J., Gong, P.: Application of satellite and GIS technologies for land-cover and land-use mapping at the rural-urban fringe: a case study. Photogrammetric Engineering and Remote Sensing 58, 439-448 (1992)

14. Xu, H.Q.: Spatial expansion of urban/town in Fuqing and its driving force analysis. Remote Sensing Technology and Application 17, 86-92 (2002)

15. Yang, C.J., Zhou, C.H.: Extracting residential areas on the TM imagery. Journal of Remote Sensing 4, 146-150 (2000)

16. Yang, S.: On extraction and fractional of urban and rural residential spatial pattern in developed area. Acta Geographical Sinica 55, 671-678 (2000)

17. Zha, Y., Gao, J., Ni, S.: Use of normalized difference built-up index in automatically mapping urban areas from TM imagery. Int. J. Remote Sensing 24, 583-594 (2003)

18. Zha, Y., Ni, S., Yang, S.: An effective approach to automatically extract urban land-use from TM imagery. Journal of Remote Sensing 7, 37-40 (2003) 